\title{
Investigation of infectious and vascular factors in the genesis of positional paroxysmal nystagmus.
}

\author{
Mahzuna Nasretinova ${ }^{1}$, Khuram Karabaev $^{2}$, and Ozod Nabiev ${ }^{1}$ \\ ${ }^{1}$ Samarkand State Medical Institute \\ ${ }^{2}$ First Tashkent State Medical Institute
}

May 19, 2020

Key points: Positional paroxysmal nystagmus-vestibular dysfunction, vascular factor, middle ear diseases, Central pathways, infectious factor

Key words: positional, paroxysmal nystagmus, cupulolithiasis, labyrinthitis.

Introduction. Short-term accompanied by severe dizziness, large-scale nystagmus, which occurs when the patient is laid on his back with a simultaneous turn of the head to the side and tilt back, is called positional paroxysmal nystagmus (PPN) $[2,3,6]$. This symptom is an important and often the only objective sign of vestibular dysfunction. PPN, first described by Bárány (1921), is observed in various diseases and injuries of the inner ear, organic processes in the posterior cranial fossa, functional disorders of the nervous system, endocrine disorders, diseases of the cardiovascular system, lesions of the cervical spine $[1,3,5,8]$.

PPN is a sign of the presence of cupulolithiasis, i.e. the formation of sediment with a high relative density in the posterior and semicircular channel of the labyrinth. Possible causes of cupulolithiasis include age-related degenerative changes in the vestibular part of the labyrinth, concussion of the inner ear with skull injuries, acute and chronic purulent otitis media, surgical interventions on the stirrups, violations of blood supply to the inner ear [4,7].

In addition, many authors consider the presence of chronic infection in the body to be an important reason for the appearance of PPN overlay. disorders that occur in the practice of an otorhinolaryngologist are often caused by the presence of an infectious focus (including acute or chronic otitis, sinusitis, tonsillitis) or (due to the wide spread of vascular pathology) disorders of the blood supply to the labyrinth and its pathways and centers.

The aim of the study was to study the influence of vascular and infectious factors on the development of positional paroxysmal nystagmus.

Materials and methods of research. This study is devoted to a comparative assessment of the value of infectious and vascular factors in the Genesis of PPN. We observed 548 patients with impaired function, including 311 women and 237 men aged 15 to 74 years, who were inpatient treatment at the clinic No. 1 of the Samarkand medical Institute and 45 of them had foci of chronic infection: chronic tonsillitis (19), chronic polypous sinusitis (12). chronic cholecystitis (8), chronic adnexitis (6). PPN was observed in 101 of 548 patients. Chronic focal infection was significantly more common in individuals who had this type of infection (14 out of 101), but in 37 out of 101 patients, it was not possible to link the occurrence of paroxysmal nystagmus with the presence of foci of chronic infection in the body.

Result of discussion. We divided all the patients under our supervision into 3 groups. Group 1 included patients with vascular disorders: atherosclerosis (46), hypertension (50), cervical osteochondrosis with 
artery syndrome (63), Meniere's disease (84), vegetative-vascular dystonia (115); group 2 patients with complications of acute and chronic purulent otitis media: with various forms of the labyrinth (109), otogenic intracranial complications (18 patients), group 363 patients with combination of vascular pathology of middle ear diseases. The data is presented in table 1.

Table 1 shows data on the frequency of paroxysmal nystagmus in patients of the above-mentioned 3 groups. Thus, in patients of group I, PPN was significantly more common $(\mathrm{P}<0.01)$ than in patients of group 2. However, this symptom was most often observed in a combination of vascular pathology and middle ear diseases. Obviously, the occurrence in this group of patients can be explained by a violation of the blood supply to the ear and the impact of a pathological process located in the middle ear on the ear labyrinth.

To determine the strength and reliability of the influence of diseases of the SOSU: the system of pathological processes in the middle ear in the Genesis of PPN in patients, we applied the method of analysis. Since violations of the function of the vestibular analyzer are observed mainly in cerebral forms of vascular pathology, we can distinguish the following gradations of the degree of intensity of the influence of the vascular factor the occurrence of paroxysmal nystagmus: 1) cerebral form of hypertension, cerebral atherosclerosis, cervical osteochondrosis with artery syndrome, vegetative-vascular dystonia with pronounced phenomena of fundus spasm (A1);2) cardinal and cardiocerebral forms of hypertension, atherosclerosis with a predominant lesion of the carotid arteries, vegetative-vascular dystonia without pronounced signs of impaired tone of the brain vessels (A2). It is obvious that the presence of a purulent focus, especially destructive processes in the temporal bone, is a greater danger of damage to the inner ear and its conducting pathways and centers than scarring changes in the tympanic cavity (adhesive otitis, tympanosclerosis). Therefore, it is also advisable to distinguish the following gradations or degrees of intensity of the influence of factor (B) (features of the pathological process in the middle ear) on the frequency of nystagmus laying:1) purulent chronic epithympanitis (B1); 2) chronic mesotimpanitis (B2); 3) cicatricial changes in the tympanic cavity (tympanosclerosis, adhesive otitis), scars of the eardrums (B3). The data is presented in table 2.

Data on the influence of factors $\mathrm{A}$ and $\mathrm{B}$ on the detection rate in 63 individuals with various forms of vascular pathology combined with diseases of the middle ear are shown in table 2, which is the basis of a two-factor uneven dispersion complex for qualitative characteristics.

The influence of factor $A$ and the total influence of organized factors $(A+A B+A B)$ are statistically significant $(\mathrm{P}<0.01)$. The influence of factor $\mathrm{B}$ (features of the pathological process in the middle ear) in 63 patients suffering from vascular diseases in combination with lesions of the middle ear was statistically insignificant, which may depend on a relatively small number of observations.

The data obtained by us indicate that changes in the vascular system were the main leading factor in the origin of PPN in patients of this group.

Based on the above, the following conclusions are obtained:

1. in the origin of PPN, vascular disorders are predominant in comparison with the influence of foci of infection, including those located in the temporal bone.

2. in patients suffering from positional labyrinth syndrome and PD, it is advisable to prescribe means that regulate vascular tone and blood supply to the inner ear.

\section{List of references:}

1. 1. Lang T.A., Sesic M. (2011) as described statistics in medicine. An annotated guide for authors, editors and reviewers. Lane. with engl. Ed. V.p. Leonov. -M.: practical medicine, -480 p.

2. Baloh R.W, Honrubia V. (2006) Clinical Neurophysiology of the Vestibular System. -New York: Oxford University Press, $-432 \mathrm{p}$

3. Nasretdinova M. T., Karabaev Kh. E., Sharafova I. A. application of diagnostic methods in patients with vertigo / / Central Asian journal of medical and natural Sciences. - 2020. - Vol. 1. - No. 1. - Pp. 29-33 
4. Nasretdinova M. T., Karabaev Kh. E. Vertigo in ENT practice / / innovative technologies in medicine for children of the North Caucasus Federal district. - 2017. - Pp. 216-219.

5. Joseph S. SEGUIN, Concise dictionary of modern medicine, new York, McGraw-hill, 2006. ISBN 97888-386-3917-3

6. Douglas M. Anderson, A. Michelle Elliott, Mosby medical, Nursing, \& auxiliary medical dictionary sesta salon, new York, USA, 2004. ISBN 88-299-1716-8

7. Singh R. K., Singh M. rhrhinolaryngology Clibics: An International Journal. 2012. Volume 4(2). P. 81-85.

8. Wolschner U., Strösser W., Weiser M., Klein P. treatment of vertigo-a combined drug that is therapeutically equivalent to dimengidrinate: results of a reference-controlled cohort study. Biol Med. 2010. Volume 30. P. 184-190.

\section{Hosted file}

Table 1NAsretdinova.docx available at https://authorea.com/users/323170/articles/452333investigation-of-infectious-and-vascular-factors-in-the-genesis-of-positional-

paroxysmal-nystagmus 